\title{
Hiperfosfatemia en la enfermedad renal crónica: incrementar la excreción renal de fósforo tal vez sea la clave para su tratamiento
}

\author{
Hyperphosphatemia in chronic kidney disease
}

Tal como Garcia Ospina y col., lo explican en su excelente artículo titulado “Importancia de la hiperfosfatemia en la enfermedad renal crónica, cómo evitarla y tratarla por medidas nutricionales", una adecuada dieta constituye uno de los pilares terapéuticos fundamentales contra el exceso sérico de fósforo en los pacientes portadores de insuficiencia renal crónica. Asimismo, cabe recordar que otras estrategias complementarias para el tratamiento de la hiperfosfatemia son:

a) reducir la absorción intestinal de fósforo mediante el uso de quelantes (carbonato de calcio, etc.), b) reducir el pasaje del fósforo del compartimiento óseo al plasmático (bifosfonatos, control del hiperparatiroidismo secundario, etc.), c) incrementar la excreción corporal de fósforo, ya sea por vía urinaria o dialítica ${ }^{1,2}$.

Con respecto a la estrategia de incrementar la excreción urinaria de fósforo, es precisamente el mecanismo que, en general, preserva al paciente enfermo renal crónico de presentar hiperfosfatemia hasta aproximadamente el final del estadio IIIb de su enfermedad (tasa de filtrado glomerular: $30 \mathrm{ml} / \mathrm{min} / 1,73$ $\mathrm{m}^{2}$ ), donde, merced al progresivo incremento de la excreción fraccional de fósforo, estimulado en parte por el ascenso sérico de la parathormona, la excreción fraccional de fósforo puede pasar de un $9 \pm 05 \%$, en personas sanas, a un $25 \pm 0,9 \%$ en pacientes insuficientes renales crónicos estadio III, hasta un $40 \pm 09$ $\%$ en nefrópatas crónicos estadío $\mathrm{V}^{3,4}$.

Sin embargo, suele ocurrir en estadios avanzados de insuficiencia renal crónica (estadios IV y V) que, pese a que sigue aumentando la excreción fraccional de fósforo en orina, su magnitud no alcanza para evitar que, a tales niveles de reducción de filtrado glomerular (tasa de filtrado glomerular $<30 \mathrm{ml} / \mathrm{min} / 1.73 \mathrm{~m}^{2}$ ), no se produzca hiperfosfatemia. Resulta entonces que, dada la escasa dializancia del fósforo, poder incrementar farmacológicamente la excreción tubular de fósforo a fin de combatir la hiperfosfatemia sería de suma utilidad no solo en la enfermedad renal crónica avanzada (estadios IV y V), sino además en el paciente en diálisis crónica con significativa diuresis residual. En este sentido, cobra importancia el concepto de procurar preservar la diuresis residual del paciente en diálisis no sólo evitando el uso de fármacos nefrotóxicos, sino también continuando el uso de inhibidores de la enzima convertidora o bloqueantes del receptor de angiotensina II (nefroprotección), y aplicando el concepto de diálisis incremental (menor dosis de diálisis) tanto en el inicio de la diálisis peritoneal como de la hemodiálisis ${ }^{5}$. Entre los fármacos que han demostrado incrementar la excreción urinaria de fósforo, bloqueando su reabsorción tubular proximal, se encuentra la indapamida, diurético que, en estudios animales, ha demostrado no sólo no reducir el filtrado glomerular sino además lograr reducir significativamente los niveles séricos e histológicos de fósforo, alcanzando un incremento dosis dependiente en la excreción fraccionales de este anión divalente del orden de hasta un $75 \pm 13 \%{ }^{6}$.

Esta es la razón por la cual hemos propuesto junto al Dr. César Restrepo Valencia realizar desde la RISRECP (Red Iberoamericana de Investigación en Salud Renal y Enfermedades Crónicas Prevalentes) un protocolo de investigación clínica a fin de evaluar el efecto de la indapamida en el control de hiperfosfatemia en pacientes portadores de enfermedad renal crónica, estudio al cual están desde ya, todos nuestros colegas invitados. 


\section{Referencias}

1. Hsu C. Calcium and phosphate metabolism in chronic renal disease. Berlin: Springer. 2006.

2. Musso CG, Guelman R, Varela F, Pidoux R, Schreck C, Rosa G, Plantalech L, Algranati L. Ibandronate improves hyperphosphatemia in dialysis patients with hyperparathyroidism. Int Urol Nephrol. 2004;36(4):625-7. Disponible en: https://doi.org/10.1007/s11255-004-2077-5

3. Musso CG, Juarez R, Vilas M, Navarro M, Rivera H, Jauregui R. Renal calcium, phosphorus, magnesium and uric acid handling: comparison between stage III chronic kidney disease patients and healthy oldest old. Int Urol Nephrol. 2012;44(5):1559-62. Disponible en: https://doi.org/10.1007/s11255-0120230-0

4. Musso CG, Rodriguez Macias E, Medina A, Heredia A, Juarez R, Rivera H, de Miguel R. Valores comparados de excreción fraccional de magnesio y fósforo peritoneal y urinario entre pacientes en diálisis peritoneal con diuresis residual, insuficiencia renal crónica (estadio III) y voluntarios sanos. Electron J Biomed 2012;3:22-26. Disponible en: http://biomed.uninet.edu/2012/n3/musso-es.html

5. Gonzalez-Sanchidrian S, Deira J. Progressive hemodialysis: Is it the future, or the present? Seminars in dialysis. 2017; 30(1): 80. Disponible en: https://doi.org/10.1111/sdi.12564

6. Plante GE, Lafreniere MC, Tam PT, Sirois P. Effect of indapamide on phosphate metabolism and vascular reactivity.Am J Med. 1988;84(1B):26-30. Disponible en: https://doi.org/10.1016/S00029343(88)90993-X

Carlos G. Musso Servicio de Nefrología

Hospital Italiano de Buenos Aires Argentina carlos.musso@hospitalitaliano.org.ar 